\title{
A tripla perspectiva: a vinda, a permanência e a volta de estudantes angolanos no Brasil
}

\author{
Dagoberto José Fonseca *
}

Resumo: Este artigo é uma reflexão sobre o papel que as universidades paulistas e paranaenses desempenham no processo de formação acadêmica dos estudantes dos Países Africanos de Língua Oficial Portuguesa (Palop), em particular os angolanos. Essa formação na instituição de ensino superior propicia novos diálogos e novas sínteses identitárias possibilitadas por outras práticas culturais apreendidas no contato com alunos, docentes, funcionários, instituições acadêmicas e de pesquisa que ignoram a realidade vivenciada por eles em Angola. Constituiremos, assim, o cenário histórico-cultural; o percurso acadêmico e identitário do estudante angolano; o contexto estudantil angolano; a história recente desse país; o lugar do intelectual e do professor universitário; o papel e o uso da língua portuguesa no Brasil e em Angola no ambiente estudantil, familiar e na rua. Buscamos entender o imaginário do jovem estudante intercambista angolano que convive com os conflitos do estigma do migrante temporário e do estereótipo do refugiado de guerra.

Palavras-chave: universidade; estudante; identidade; imaginário; intercâmbio.

\section{The triple perspective for Angolan students in Brazil: arriving, returning and staying}

Abstract: This article is a reflection about the role that the São Paulo and Paraná State Universities play in developing the academic educational process of Portuguese-speaking African or PALOP students, especially Angolan students. Working on a degree at a higher education institution fosters new dialogues and new identity syntheses made possible by different cultural practices learned in the contact with students, professors, employees, academic institutions and research institutions that ignore people's daily life conditions in Angola. This text includes views on the Angolan historical-cultural scene, the Angolan students' academic route and identity, the present student environment in Angola, the recent history of this country; the intellectuals and university professors' social positions, and the role and use of the Portuguese language in Brazil and in Angola in scholar, familiar and colloquial situations. The study has been an attempt to understand the imaginary world of young Angolan exchange students who have to face the conflicts of the temporary migrant and the war refugee stereotypes.

Key words: university; student; identity; imaginary world; exchange.

* Departamento de Antropologia Política e Filosofia, Faculdade de Ciências e Letras de Araraquara, Universidade Estadual Paulista Júlio de Mesquita Filho (Unesp). Coordenador do Centro de Estudos das Culturas e Línguas Africanas e da Diáspora Negra (Cladin) e do Laboratório de Estudos Africanos, Afro-Brasileiros e da Diversidade (Lead). Araraquara, SP, Brasil. dagobertojose@gmail.com 


\section{Introdução}

Este artigo visa estabelecer um conjunto de reflexôes, análises e interpretações referentes à presença de estudantes africanos oriundos dos países de língua oficial portuguesa no Brasil, em particular em instituições de ensino superior situadas nos Estados de São Paulo e Paraná. Ater-nos-emos, de modo particular, ao convênio assinado, no ano de 2004, entre a Fundação para o Vestibular da Unesp (Vunesp) e a Fundação Eduardo dos Santos (Fesa). Esse convênio foi a primeira e, até o momento, única experiência de um processo seletivo estruturado, administrado, aplicado e corrigido por uma fundação vinculada a uma universidade brasileira em outro país, a fim de captar estudantes estrangeiros — no caso, angolanos —, mediante a utilização de vagas disponíveis nos diversos cursos das diferentes áreas do conhecimento dessas instituiçôes de ensino. Com base nesse histórico é que traçaremos uma interpretação dos novos diálogos e das novas sínteses identitárias constituídas por esses estudantes angolanos presentes em São Paulo e no Paraná, mas também demonstraremos que as instituiçôes acadêmicas ignoram a realidade vivenciada por esses estudantes em Angola, na medida em que desconhecem a realidade social desse país africano.

Dessa maneira, constituiremos um breve panorama do triplo cenário que envolve esses estudantes angolanos, ou seja: 1) o histórico-cultural; 2) o percurso acadêmico e identitário do estudante angolano, o contexto estudantil angolano; 3) a história recente desse país, o lugar do intelectual e do professor universitário, o papel e o uso da língua portuguesa no Brasil e em Angola no ambiente estudantil, familiar e na rua.

Buscamos entender o imaginário do jovem estudante intercambista angolano que convive com os conflitos do estigma do migrante temporário e o estereótipo do refugiado de guerra, mas que sonha em voltar para o seu país natal e contribuir com a sua reconstrução após a guerra civil que se encerrou em 2002. No entanto, é atraído para permanecer no Brasil devido ao conjunto de facilidades e à constituição de uma nova identidade social, forjada no contexto das relaçôes adquiridas nesse período de juventude. Até porque em São Paulo e no Paraná essa população está dialogando com novos sujeitos — os jovens que encontram na festa, no lazer e no estudo - uma liberdade e um futuro a ser construído longe ou perto da instituição familiar.

\section{Diplomacia, política, migração e intercâmbio estudantil no Atlântico Sul - o papel do Itamaraty}

As universidades no Brasil, particularmente aquelas situadas no eixo Rio de Janeiro-São Paulo, como a Universidade Federal do Rio Janeiro (UFRJ), a Uni- 
versidade Estadual do Rio de Janeiro (UERJ) e a Universidade de São Paulo (USP), receberam neste último quartel do século XX um número significativo de estudantes estrangeiros oriundos de diversos países latino-americanos e africanos, mediante convênios assinados com diversos organismos internacionais e universidades desses países. Mas o maior fluxo de estudantes universitários veio do continente africano, através do Programa de Estudante Convênio de Graduação (PEC-G), vinculado aos Ministérios das Relações Exteriores (MRE) e da Educação (MEC).

O PEC-G foi criado no final da década de 1920 e administrado exclusivamente pelo MRE, até 1967. Atualmente, ele está pautado por acordos e protocolos conjuntos entre o MEC e o MRE, com a participação das missões diplomáticas e das repartiçôes consulares do Brasil no exterior. Os protocolos possuem regulamentações específicas e próprias balizadas pelo Estatuto do Estrangeiro (Lei no 6.815/80; Lei 6.964/81; e Decreto no 86.715/81), segundo nos informa Edilma Desidério (2005). Nesses acordos o sistema federal de ensino vincula esses estudantes às instituiçôes de ensino superior (IES), sejam as privadas, sejam as públicas. No entanto, nem todas as instituições estão regulamentadas e autorizadas pelo sistema federal de ensino a receber estudantes oriundos do PEC-G, quer pelas questôes de ordem técnica e administrativa, quer pelas avaliações políticas, acadêmicas e pedagógicas que são processadas pelo MEC.

Os acordos de cooperação técnico-científica, acadêmica, cultural e tecnológica das universidades brasileiras e do Estado brasileiro com os países africanos estão orientados no contexto da globalização, sobretudo para a luta contra a pobreza, a desigualdade e a exclusão, para o desenvolvimento sustentável e para o estreitamento das relações políticas e econômicas como dimensão prioritária da cooperação. Tomando-se como base o processo migratório do africano para o Brasil, que se forma a partir dessas políticas, buscamos analisar em três tempos: (i) as políticas de cooperação institucional para a educação superior de graduação e pós-graduação; (ii) os acordos de cooperação técnica, científica, social e cultural de transferência e intercâmbio em áreas diversas; (iii) a migração estudantil e os fluxos estimulados pelos Acordos de Cooperação, como uma reflexão. Como considerações finais, fazemos uma reflexão sobre a relevância dos acordos como fortificadores de laços econômicos e sociais; contudo, no que concerne à política de cidadania e bem-estar dos imigrantes africanos, ainda haveria muito por fazer (Desidério, 2005).

É importante considerar o papel político desempenhado pelo MRE (Itamaraty) nesse processo educacional que se traduz na migração e no intercâmbio internacional de estudantes africanos como um fator decisivo para o momento que analisamos hoje. E entender que a política empreendida pelo 
MRE nos anos de turbulência institucional aqui e no continente africano, devido às lutas de independência, deu o tom para a presença significativa desses estudantes africanos. A gestão de Jânio Quadros e, após, a de João Goulart e a ditadura militar foram fundamentais para o que assistimos hoje, sobretudo com relação aos países do Palop.

Argumentou Quadros que a nova política africana do Brasil, inspirada nas independências das jovens naçôes do outro lado do Attântico, seria uma "modesta recompensa" pelo imenso débito que o Brasil tinha para com o povo africano. E já bastavam as "consideraçôes de ordem moral" para justificar a dimensão atlântica da política externa do Brasil. Chegou a afirmar, de forma contundente, que a África próspera e estável seria condição essencial à segurança e ao desenvolvimento do Brasil (Saraiva; Gala, 2008).

A mensagem de Jânio Quadros, no dia 15 de março de 1961, endereçada ao Congresso Nacional, não deixa dúvida quanto ao caminho a ser seguido pelo Brasil e pela diplomacia brasileira com relação à África e ao contexto colonial, como afirmam Saraiva e Gala (2008):

O dado concreto éo de que, a partir de 1961, diante da formulação pessoal de Jânio Quadros em sua memorável mensagem ao Congresso Nacional de 15 de março, o Atlântico Sul se fez mais brasileiro. Definindo a nova política exterior do Brasil como um instrumento contra o colonialismo e o racismo e sublinhando o apoio brasileiro ao princípio da autodeterminaçăo dos povos da África, o presidente avocou para si a responsabilidade maior da sua própria formulação. Sustentou que o Brasil tinha aspirações comuns com a África, como o "desenvolvimento econômico, a defesa dos preços das matérias-primas, a industrialização e o desejo de paz". E deixou também claro que essa nova dimensáo era o resultado das necessidades do crescimento interno do país.

Após o governo de Jânio Quadros, constatamos que o Brasil desempenhou um papel relativamente importante nos debates internacionais quanto ao processo de independência dos países africanos, estabelecendo o reconhecimento político das naçóes africanas independentes, criando departamentos e divisões com o olhar para a África dentro do Itamaraty.

A primeira tradução objetiva das novas inclinações africanistas da diplomacia brasileira apareceu na reforma administrativa do Ministério das Relações Exteriores, o Itamaraty, em 1961. Com 
ela nascia uma nova unidade administrativa no ministério: a Divisão da África. Ela abrigaria os diplomatas brasileiros que estiveram envolvidos nos assuntos africanos nas Nações Unidas na década de 1950. A segunda seria a inclusão no Relatório do mesmo Itamaraty, a partir de 1961, de capítulo especificamente voltado para os assuntos africanos, para a descrição das posições brasileiras relativas àquele continente e o sumário das atividades desenvolvidas a cada ano. A terceira medida concreta foi a criação de um grupo de trabalho no interior da chancelaria que teria dois objetivos imediatos: formular propostas sobre as possibilidades de abertura de novas missōes diplomáticas e consulares junto aos novos Estados africanos e estudar formas objetivas de estabelecimento de vínculos econômicos e culturais com o continente africano (Saraiva; Gala, 2008).

Essa conjuntura e o papel político do MRE propiciaram o caldo cultural que nos possibilita constatar que a presença dos estudantes africanos, sobretudo a partir das últimas décadas do século XX, em nossas universidades, também está assentada em projetos de constituição de hegemonia e de uma leitura geopolítica no Atlântico Sul, como sublinhou o Gen. Golbery do Couto e Silva, já no bojo da ditadura militar brasileira, após a visita de 19 a 25 de setembro de 1964 do presidente do Senegal, Léopold Sedar Senghor, como afirmam Saraiva e Gala (2008):

O Senegal ocupava posição estratégica na teoria do "hemiciclo interior”, nas interpretações do General Golbery do Couto e Silva. Dacar era o outro lado do estreito que unia Natal, no nordeste brasileiro, área de ocupação prioritária desde a Segunda Guerra Mundial. A visita do primeiro presidente africano, que nunca foi um esquerdista radical, era uma feliz oportunidade para os geopolíticos instalados no governo fazerem alianças no outro lado do Atlântico.

Foi nesse contexto que o Brasil se tornou, no período ditatorial - e retomou esse papel nos governos da denominada Nova República —, um país com o olhar mercantil e geopolítico voltado para o continente africano, propiciando que no decorrer desse processo houvesse assinaturas desses convênios de intercâmbio estudantil envolvendo as instituições de ensino superior (IES) mencionadas, particularmente aquelas do eixo Rio de Janeiro-São Paulo. Mas também se constata a participação de universidades da região sul do país e do Distrito Federal, nesse último período, participando desse processo.

Segundo dados do Departamento de Polícia Federal, no ano de 2005 havia um total de 1.399 estudantes, distribuídos nos estados do Brasil. O maior 
número estava em São Paulo (354) e no Rio de Janeiro (306). A escolha por esses estados deu-se fundamentalmente pela maior oferta de cursos pretendidos nas IES e pelo fato de serem estados mais apresentados aos estudantes africanos, sobretudo pela mídia eletrônica e televisiva. Além disso, há a divulgação pela própria diplomacia brasileira presente nesses países africanos, por serem esses estados grandes centros urbanos, tecnológicos, científicos e culturais do Brasil.

Ao longo dos primeiros anos do século XXI, verificamos que os países africanos com o maior número absoluto de estudantes universitários no Brasil são as nações integrantes dos Países Africanos de Língua Oficial Portuguesa (Palop). Esse processo dá-se pelos motivos já conhecidos, tais como a língua portuguesa, o processo de conquista colonial lusitano, os laços culturais e étnico-raciais. Esses dados são constatáveis nas tabelas abaixo, propiciadas pelo estudo de Irene Vida Gala (2007):

\section{ANEXO IV}

Alunos inscritos no Programa Estudante Convênio de Graduação

\begin{tabular}{|l|r|r|r|r|r|r|r|r|}
\hline \multicolumn{1}{|c|}{ África } & $\mathbf{2 0 0 0}$ & $\mathbf{2 0 0 1}$ & $\mathbf{2 0 0 2}$ & $\mathbf{2 0 0 3}$ & $\mathbf{2 0 0 4}$ & $\mathbf{2 0 0 5}$ & $\mathbf{2 0 0 6}$ & TOTAL \\
\hline Angola & 2 & 20 & 29 & 23 & 33 & 11 & 31 & $\mathbf{1 4 9}$ \\
Cabo Verde & 117 & 64 & 227 & 263 & 192 & 230 & 314 & $\mathbf{1 4 0 7}$ \\
Camarões & 0 & 0 & 1 & 0 & 0 & 0 & 0 & $\mathbf{1}$ \\
Costa do Marfim & 1 & 0 & 0 & 1 & 1 & 0 & 0 & $\mathbf{3}$ \\
Gabão & 0 & 11 & 0 & 2 & 1 & 1 & 3 & $\mathbf{1 8}$ \\
Gana & 4 & 3 & 7 & 9 & 11 & 6 & 3 & $\mathbf{4 3}$ \\
Guiné-Bissau & 36 & 87 & 111 & 97 & 58 & 186 & 159 & $\mathbf{7 3 4}$ \\
Marrocos & 0 & 1 & 0 & 0 & 0 & 0 & 0 & $\mathbf{1}$ \\
Moçambique & 13 & 14 & 27 & 21 & 26 & 27 & 13 & $\mathbf{1 4 1}$ \\
Namíbia & 1 & 1 & 0 & 0 & 0 & 0 & 0 & $\mathbf{2}$ \\
Nigéria & 9 & 7 & 7 & 11 & 14 & 27 & 19 & $\mathbf{9 4}$ \\
Quênia & 0 & 4 & 14 & 14 & 11 & 12 & 5 & $\mathbf{6 0}$ \\
São Tomé \& Príncipe & 0 & 0 & 24 & 0 & 47 & 147 & 35 & $\mathbf{2 5 3}$ \\
Senegal & 7 & 2 & 4 & 1 & 1 & 3 & 5 & $\mathbf{2 3}$ \\
\hline Total & $\mathbf{1 9 0}$ & $\mathbf{2 1 4}$ & $\mathbf{4 5 1}$ & $\mathbf{4 4 2}$ & $\mathbf{3 9 5}$ & $\mathbf{6 5 0}$ & $\mathbf{5 8 7}$ & $\mathbf{2 9 2 9}$ \\
\hline
\end{tabular}

Fonte: Divisão de Temas Educacionais/MRE. Novembro de 2006. 
Programa de Estudantes-Convênio de Pós-Graduação Ingresso de estudantes africanos de 2000 a 2006

\begin{tabular}{|c|c|c|c|c|c|c|c|}
\hline PAÍS/ANO & 2001 & 2002 & 2003 & 2004 & 2005 & 2006 & Total por país \\
\hline \multicolumn{8}{|l|}{ África } \\
\hline Angola & 1 & 6 & 3 & 1 & 2 & 3 & 16 \\
\hline Cabo Verde & 4 & 5 & 5 & 6 & 12 & 22 & 54 \\
\hline Costa do Marfim & & 2 & 1 & 1 & 3 & 1 & 8 \\
\hline Gana & & & 1 & & & & 1 \\
\hline Guiné-Bissau & 1 & 3 & 1 & 1 & 6 & 5 & 17 \\
\hline Moçambique & 5 & 9 & 5 & 8 & 12 & 16 & 55 \\
\hline Namíbia & 1 & & & & & & 1 \\
\hline Nigéria & & & 1 & & 1 & & 2 \\
\hline São Tomé e Príncipe & 1 & & & & 4 & & 5 \\
\hline Senegal & 2 & & & & & 1 & 3 \\
\hline Total por ano & 15 & 25 & 17 & 17 & 40 & 48 & 162 \\
\hline
\end{tabular}

Outro fator importante, que fez com que as nações de língua oficial portuguesa enviassem seus jovens para o Brasil, também se vincula ao papel político desempenhado pelo Brasil quando do reconhecimento da independência de Angola em 1975, sinalizando um processo de atração das antigas colônias portuguesas de ultramar para a sua órbita regional no Atlântico Sul e atendendo algumas demandas políticas dessas recentes naçóes independentes da costa oriental desse vasto oceano. A diplomacia brasileira e o olhar agudo do Gen. Golbery do Couto e Silva e de outros estrategistas da geopolítica brasileira estabeleceram a ruptura com a antiga política defendida pela ditadura salazarista e colocaram o Brasil como país que dava apoio logístico e estratégico a Angola, como havia feito Jânio Quadros na década de 1960, em função da dimensão histórica e étnicocultural existente entre esses dois países irmãos, a despeito das leituras ideologizadas presentes no contexto da Guerra Fria (Saraiva; Gala, 2008).

\section{A Unesp e a UFPR - o contato com a Fundação Eduardo dos Santos (Fesa)}

Após a independência de Angola de Portugal em 1975, constatou-se que muitos jovens universitários angolanos deixaram de ir estudar no Colégio do 
Império e em outras universidades lusas, como as tradicionais Coimbra e Lisboa. Nesse contexto, abriu-se um novo fluxo migratório de caráter acadêmico angolano nas décadas posteriores, particularmente para os países do Leste Europeu e para Cuba, devido aos acordos e tratados de cooperação científica, tecnológica, cultural, econômica e militar do partido governista, o Movimento Popular de Libertação de Angola (MPLA), com as nações que constituíam o bloco dos países socialistas. A formação da nova intelectualidade e dos dirigentes angolanos esteve baseada nas teses marxistas e leninistas e alicerçada pelo socialismo real e pelas teorias da economia planificada.

No entanto, essa nova fronteira estudantil aberta pelos angolanos nos países da Cortina de Ferro e em Cuba não fez com que se extinguisse o fluxo migratório estudantil para Portugal. Porém foi acompanhada de um aumento paulatino do número de jovens estudantes que vieram estudar nas universidades brasileiras, quer pela facilidade da língua, já que o Estado angolano também havia estabelecido a língua portuguesa como a sua língua oficial, quer pelo fato de que Brasil e Angola estavam cada vez mais próximos, particularmente por ser o Estado brasileiro o primeiro país do mundo a reconhecer as legítimas aspiraçôes do povo angolano de realizar a sua independência.

As universidades brasileiras iniciaram nas últimas décadas uma ação concorrencial com as tradicionais instituições de ensino superior de Portugal que visavam, ainda, inculcar a mentalidade colonial nesses jovens estudantes angolanos. As IES brasileiras, particularmente as públicas, também estabeleciam disputas com os países do bloco socialista por esses jovens universitários como parte de uma leitura da geopolítica internacional, realizada pela diplomacia e pelos estrategistas do Planalto da Alvorada, no contexto dos países do Attântico Sul, aproveitando-se dos últimos suspiros dados pelo império socialista no final dos anos 1980.

Nesse contexto, constatamos que as universidades brasileiras receberam, no início do século XXI, uma quantidade significativa de estudantes angolanos, muitos dos quais vieram mediante o Programa de Estudante Convênio de Graduação (PEC-G). No entanto, há aqueles que estão estudando em IES do Brasil, mas vinculados a convênios estabelecidos entre a Fundação Eduardo dos Santos (Fesa) e essas instituiçōes brasileiras (universidades, centros universitários, faculdades e centros tecnológicos). Os estudantes estão concentrados em diversos cursos, na maior parte das faculdades e universidades privadas e públicas fluminenses, paulistas e paranaenses.

A Fesa é uma organização não-governamental de explícito apoio logístico e técnico ao povo angolano, atuando como parceira do governo angolano no desenvolvimento do país, tendo como patrono o Presidente da República de Angola, o Engenheiro José Eduardo dos Santos. Ela possui filiais espalhadas 
pelo mundo, tendo sede na cidade de Luanda. No Brasil, ela está situada na cidade do Rio de Janeiro, tendo firmado inúmeros convênios com instituições diversas, entre as quais universidades privadas e públicas.

Segundo E. Desidério (2005), no período de 2003 havia nos estados do Rio de Janeiro e do Paraná as seguintes instituições conveniadas com a Fesa: Fundação Educacional Rosemar Pimentel - Ferp - campi de Nova Iguaçu e Volta Redonda; Universidade Estadual Norte Fluminense - Uenf (Campos); Universidade Estadual do Rio de Janeiro - Uerj (campus Maracanã); Universidade Nova Iguaçu - Unig (Nova Iguaçu - Acordo Novo e Antigo); Universidade Cidade - UniverCidade (Unidade Lagoa e Centro); Universidade Tuiuti do Paraná (Curitiba); Universidade Federal do Paraná - UFPR (Curitiba). O total de estudantes conveniados nos dois estados era de 132. Adalbert Adam, à época vice-presidente do escritório da Fesa no Rio de Janeiro e seu representante na América Latina, estimava, em 2004, cerca de "450 estudantes angolanos no Brasil, do ensino fundamental ao superior"

Segundo se depreende do site do Jornal Angola Hoje, a Fesa havia assinado novos acordos, em 2004: ${ }^{2}$

Além desses, novos acordos já foram assinados entre a Fesa e a Universidade Estadual Paulista (Unesp), Universidade de São Paulo (USP), Universidade Estadual de Campinas (Unicamp), Universidade Federal de Sergipe (UFS) e Universidade Federal da Bahia (UFBA), que em breve estarão recebendo estudantes angolanos. Outros convênios estão sendo estudados com diversas universidades brasileiras.

O convênio com a Unesp e a Fundação para o Vestibular da Unesp (Vunesp) foi realizado com o trabalho de articulação, de apoio e de incentivo do Núcleo Negro da Unesp para a Pesquisa e Extensão (Nupe) ${ }^{3}$, com o intuito de realizar

o primeiro vestibular de uma universidade brasileira fora do território nacional. Este processo deu-se a partir da construção de parceria entre esses dois organismos da Unesp e o convênio assinado entre a Fundação Vunesp e a Fesa de Angola. O vestibular respalda e estabelece a criação do consórcio entre as universidades brasileiras capitaneadas pela Unesp, tendo a parceria

I. $\quad<$ http://www.fesa.org.br/Imprensa/AngolaHoje/2005/Set-Out/pag I 7.htm>.

2. <http://www.fesa.org.br/Imprensa/AngolaHoje/2004/Mai-Jun/pagl8.htm>.

3. O Nupe é um Núcleo de Estudos Afro-Brasileiros que visa estimular, problematizar e fomentar as atividades de pesquisa, de ensino e de extensão no interior da Universidade Estadual Paulista "Júlio de Mesquita Filho" - Unesp —, tendo como foco a população negra no Brasil e no exterior. 
entre o Nupe-Vunesp e a Fesa como articuladores deste processo (Fonseca, 2005, p. 1).

Fonseca (2005, p. 1) ainda informa que

no vestibular tivemos já a presença da Universidade Federal do Paraná, neste consórcio, oferecendo 48 vagas para os estudantes angolanos para este ano de 2005, nos seus principais cursos. A UNESP ofereceu 90 vagas, sendo todas nas áreas de Ciências Exatas e Biológicas, perfazendo um total de 138 vagas que deverão ser ocupadas pelos estudantes deste país irmão do continente africano.

Essa iniciativa inédita na história das universidades brasileiras trouxe a possibilidade de buscar os talentos de outros países - no caso, os angolanos - a partir de um exame de seleção que ocorreu em solo africano, mais especificamente nas cidades de Luanda, Benguela, Cabinda, Lubango. A Unesp, a Vunesp $\mathrm{e}$, particularmente, o Nupe não queriam que os estudantes angolanos que viessem estudar no Brasil mediante esse convênio fossem exclusivamente os filhos das famílias endinheiradas da sociedade angolana ou os familiares e agregados de membros do partido no governo. Buscava-se, com isso, estabelecer um outro recorte nas relaçôes com os africanos e, particularmente, aqueles integrantes dos Palop, sobretudo porque era também um momento em que a Unesp iniciava o seu debate interno sobre as políticas de açōes afirmativas para a população de descendência africana com recorte também socioeconômico. Desse modo, esse processo de seleção no país de origem do estudante estrangeiro levava em conta as críticas que se davam com relação àqueles estudantes provenientes do PEC-G de origem africana que estavam em diversas IES brasileiras, oriundos geralmente dos segmentos mais abastados do país.

O Prof. Dr. Alvanir de Figueiredo ${ }^{4}$ dizia as condições estabelecidas para a Vunesp:

À Vunesp caberá a incumbência de selecionar estudantes angolanos para freqüência a cursos universitários, cujas vagas adicionais foram disponibilizadas através de convênio, que desta vez irmana duas universidades públicas de tradição e porte: Universidade Federal do Paraná e Universidade Estadual Paulista. Trata-se de experiência que terá continuidade com a participação de outras instituições brasileiras públicas e privadas, em todo o território nacional.

4. Àépoca, Presidente da Vunesp. Mensagem aos candidatos do Exame de Acesso 2005 - Vestibular em Angola para universidades do Brasil (Manual de apresentação, 2004, p. I). 
Com a tradição de seriedade, sigilo e rigor com que executa há mais de 25 anos exames vestibulares, ou de acesso, e concursos no Brasil, a Vunesp sente-se honrada e orgulhosa em ser a pioneira em levar tais exames até Angola, cuja ligação histórica com o Brasil é reforçada pela manutenção da lusofonia e laços culturais.

E o Presidente da Fesa, o embaixador Ismael Diogo dos Silva, dizia quais eram os anseios dessa iniciativa conduzida no sentido de possibilitar que mais jovens angolanos pudessem preparar-se no Brasil para, em futuro próximo, retornar e contribuir com o esforço de reconstruir a nação destruída pela guerra civil:

Todos os anos jovens angolanos de diferentes extractos e condição social vão estudar ao Brasil, aproveitando uma oportunidade ímpar criada com o sistema de bolsas de estudo que a Fundação Eduardo dos Santos tem disponibilizado, em resultado de convênios e acordos com Universidades e instituições de Ensino Superior daquele País. Vários anos depois do início deste processo, é com orgulho que anunciamos a realização do Primeiro Vestibular Unificado para Universidades Brasileiras no Exterior, a prova que vai seleccionar candidatos angolanos à freqüência de cursos superiores em Universidades brasileiras de alto nível. Uma experiência inédita que levará a chancela da Fesa, em reconhecimento pela seriedade, maturidade e profissionalismo que tem demonstrado no tratamento desta matéria.

Reafirmamos aqui, uma vez mais, o envolvimento da Fundação Eduardo dos Santos em acçōes de grande impacto social, sobretudo na área da Educação já que, reconhecidamente, só com gente formada, educada e devidamente preparada Angola poderá aspirar a tornar-se num País de nível onde os seus filhos estarão habilitados a dar respostas aos desafios que a luta pelo desenvolvimento coloca. ${ }^{5}$

Com esse convênio, a Fesa dava mais um passo para ampliar o leque de parceiros institucionais em prol da formação de quadros para o futuro do desenvolvimento social de Angola. Por outro lado, afirmava que esse processo só se manteria com o apoio da sociedade angolana, isto é, das suas instituições, das empresas e dos familiares desses 138 jovens que iriam estudar nessas duas respeitadas universidades do eixo sul-sudeste do Brasil. Segundo nos informa o site da Fesa sobre a primeira etapa que trouxe os estudantes em abril de 2005:

5. Mensagem aos candidatos do Exame de Acesso 2005 - Vestibular em Angola para universidades do Brasil (Manual de apresentação, 2004, p. I). 
Nessa primeira etapa vieram apenas 85 , em vôo especial da TAAG, empresa aérea angolana. O governo de Benguela e algumas empresas privadas concederam bolsas de manutenção aos estudantes. ${ }^{6}$

Tal medida justifica-se porque, sabidamente, nem todos os possíveis selecionados poderiam contar com recursos financeiros para manter-se nas cidades do interior paulista, onde se situam os campi da Unesp que receberiam esses/as jovens, e na cidade de Curitiba, onde se localiza o campus da UFPR.

Dessa maneira, o presidente da Fesa já informava aos candidatos na apresentação do edital do exame de seleção o seguinte:

Os cento e trinta e oito jovens de diferentes extractos sociais que forem seleccionados terão assim a sua grande oportunidade de fazer uma formação de qualidade em Universidades do mais alto nível do Brasil sendo-lhes exigível, apenas, a observância dos preceitos elementares para concursos desta natureza. Deste modo estaremos a defender a prática mais elementar de justiça, uma das bandeiras da nossa Fundação. Este exercício, enquanto iniciativa patrocinada pela Fesa, deve significar um esforço conjunto da Sociedade angolana, envolvendo as famílias dos estudantes e todas as Organizaçōes da sociedade, já que, importa referir, há a comparticipação dos encarregados de educação, familiares ou outros, para suportar parte dos custos da formação. ${ }^{7}$

Ficam nítidos nas palavras do Embaixador Ismael Diogo da Silva os objetivos do convênio e a necessidade do envolvimento da sociedade e dos familiares, sem mencionar nesse contexto o governo e o partido governista, explicitando a necessidade de todos os setores socioeconômicos estarem representados nesse exame e em condições de serem selecionados. Mas, também, outra preocupação adicional quanto à presença dos menos favorecidos economicamente nesse processo era o apoio financeiro de empresas e instituiçóes, particularmente para a manutenção desses jovens angolanos com um recurso mínimo de US\$ 500.00 por mês, nos cursos de Ciências Biológicas, e de US\$ 300.00 mensais, nos cursos tecnológicos e de Ciências Exatas. Nesses cursos - particularmente nos de medicina e odontologia, em que há necessidade de adquirir o quite branco - há exigência de compra de equipamentos pessoais e outros insumos para a realização de disciplinas. A Fesa/Brasil era a responsável pelo acompanhamento, pela supervisão do aproveitamento acadêmico de todos os alunos

6. Fonte: <http://www.fesa.og.ao/noticias/not_21.htm>. Acesso em: I 8 set. 2008.

7. Mensagem aos candidatos do Exame de Acesso 2005 - Vestibular em Angola para universidades do Brasil (Manual de apresentação, 2004, p. I). 
angolanos oriundos desse convênio. Essa responsabilidade não poderia recair sobre a universidade direta e formalmente, mas o documento presente no edital do exame de seleção (2004, p. 13) estabelece que:

Os alunos terão o seu aproveitamento acadêmico regulamentado pelas normas da instituição que os recebe. A regulamentação e a validação dos diplomas serão de responsabilidade da Fesa, que as fará junto aos órgãos competentes (Itamarati, Consulado/Embaixada de Angola no Brasil e Embaixada do Brasil em Angola).

Esse processo inédito na história das relaçôes internacionais entre IES brasileiras e instituiçôes estrangeiras, como a Fesa, não teve a compreensão do MRE e do MEC, o que dificultou o andamento das documentaçôes de embarque dos selecionados angolanos. Os entraves ocorreram quer na embaixada brasileira em Luanda (Angola) para fazer os encaminhamentos dos vistos temporários, quer no próprio MRE, em Brasília, que não entendia ou não estava preparado para lidar com esse ineditismo. Por outro lado, o MEC, na figura do seu então Secretário de Ensino Superior, Nelson Máculan Filho, compreendia que esse passo era fundamental e deveria ser dado por outras IES do país. A despeito disso, o MEC também não conseguia desenvolver a contento e com a rapidez necessária o processo de migração desses jovens angolanos.

Com essas dificuldades de ordem administrativa, burocrática e diplomática, esses jovens somente chegaram ao Brasil (São Paulo e Paraná) no dia 22 de abril de 2005, já com os cursos em andamento e muitos chegando em momentos de atividades de avaliação do primeiro semestre letivo em suas unidades universitárias da Unesp e da UFPR, o que evidentemente causou certo prejuízo para esses jovens e impossibilitou que muitos deles pudessem ter o tempo de adaptação necessário à vida universitária paulista e paranaense. No entanto, o que foi feito no Instituto de Biociências, Letras e Ciências Exatas (Ibilce) — campus de São José do Rio Preto, na Unesp - foi adotado em diversas unidades universitárias e cursos dessa universidade e da UFPR, como se apreende desta informação presente no site da Unesp: "o Ibilce também definiu, junto aos coordenadores dos cursos envolvidos, uma estratégia para a recuperação dos conteúdos ensinados a partir do início do ano letivo". ${ }^{8}$

$\mathrm{O}$ atraso na vinda para o Brasil acarretou um sério desdobramento institucional e pessoal para esses alunos. O primeiro problema foi o fato de que se abria um novo procedimento de migração de jovens estudantes, diferente daquele realizado pelo PEC-G nas diversas embaixadas brasileiras dos países

8. Fonte: <http://www.universia.com.br/html/noticia/noticia_dentrodocampus_bjfhf.html>. Matéria do dia 03 de maio de 2005, com o título "Angolanos na Unesp/São José do Rio Preto". 
africanos, além da denúncia da dificuldade de nossas instituiçóes diplomáticas, administrativas e burocráticas em reconhecer e aceitar um novo mecanismo institucional aberto pelo próprio MRE nas últimas décadas do século $\mathrm{XX}$, referente ao seu diálogo com a África e com os Palop, em particular. O segundo foi o fato de esses jovens não terem tido tempo para ambientar-se em solo brasileiro: muitos tiveram problemas com a alimentação, com os nossos costumes e com a nossa maneira de construir o pensamento lógico, além da saudade dos familiares, que já se abateu nos primeiros dias no Brasil, fazendo muitos quererem voltar a Angola. Em matéria do dia 31/08/2007, os depoimentos de estudantes desse convênio que estão na Unesp - campus Sorocaba - revelam tais ocorrências:"

Adaptação, aliás, foi algo que nem todos assimilaram bem. A despeito dos mais de dois anos no Brasil, alguns ainda se dizem em "estado de adaptação". É o que afirma Olga, para quem a saudade do pai, grande incentivador, é o que mais incomoda. Para Sandra, o problema aparece na hora das refeiçōes: "Em Angola não é costume comermos todos os dias o mesmo prato, como aqui se faz com arroz e feijão; parece estranho". Pedro, por sua vez, diz que o maior problema parece estar confinado nos muros da faculdade: "A grade curricular é muito extensa, pesada demais". Pedro, aliás, mostrou-se chocado com os trajes despojados com os quais os universitários daqui freqüentam as aulas e com a excessiva quantidade de fumantes entre os jovens e adolescentes: "Em meu país se vai à faculdade de traje social e fumantes só são vistos em círculo de adultos".

No entanto, também podemos observar que em outros campi da Unesp, como é o caso de alguns estudantes que foram para São José do Rio Preto, no Ibilce, houve um processo rápido de adaptação, o que demonstra que a realidade sociocultural e psíquica é diferente para um e para outro jovem. Segundo nos informam estes estudantes:

A adaptação dos novos alunos ao Brasil está sendo rápida. "O campus é bom e oferece um ambiente agradável para os estudos e para a convivência. As pessoas são receptivas, alegres e estão sempre dispostas a ajudar", diz Délcio de Jesus Machado, gra-

9. Fonte: <http://www.universia.com.br/noticia/materia_dentrodocampus.jsp?not=38700>. Com o título: "Estudantes angolanos da UNESP Sorocaba são tema de reportagem em jornal local". Os estudantes são Nguema Valentim Caxala Caiombo, 25, Pedro Francisco Joaquim Lourenço, 22, alunos do curso de engenharia de controle e automação, e Olga de Sousa Tinta, 27, e Sandra Cristina Domingos Bambi, 26, discentes de Engenharia Ambiental. Eles foram entrevistados pelo jornal O Cruzeiro do Sul, diário local de Sorocaba. 
duando de Ciências da Computação, proveniente de Luanda. "Vejo no curso a oportunidade de ocupar ótimos cargos em meu país e a possibilidade de complementar a sua formação, equivalente ao curso técnico em Informática.” Ana Paula Domingos de Carvalho e Lilia Wimbo Guilherme Alberto, estudantes, respectivamente, de Engenharia de Alimentos e de Ciências da Computação, possuem formação diversa dos cursos escolhidos. Ana Paula é técnica em Enfermagem e Lilia é pedagoga. Ambas acreditam que a experiência acadêmica e cultural será enriquecedora. "Sempre gostei de computadores. Quanto ao curso, ele me possibilitará uma compreensão maior do desenvolvimento tecnológico, tão presente em nosso cotidiano, e minha profissionalização na área”, explica Lilia. ${ }^{10}$

Observamos também esse processo adaptativo bem articulado entre a instituição universitária e os alunos angolanos oriundos do convênio, quando encontramos um Grupo de Trabalho do Nupe na faculdade, como é o caso da Faculdade de Arquitetura, Artes e Comunicação (Faac) no campus de Bauru. Os alunos têm freqüentado diversos espaços da coletividade negra paulista, entre os quais o Baile do Carmo, na cidade de Araraquara, em que estiveram como convidados pela organização desse evento tradicional, acompanhados do jornalista Silvestrinho, da Rádio Unesp Bauru e de Vagner Silvestre, da Assessoria de Comunicação dessa unidade universitária. Abaixo, algumas fotos ${ }^{11}$ exemplares do processo de adaptação desses jovens presentes no baile.
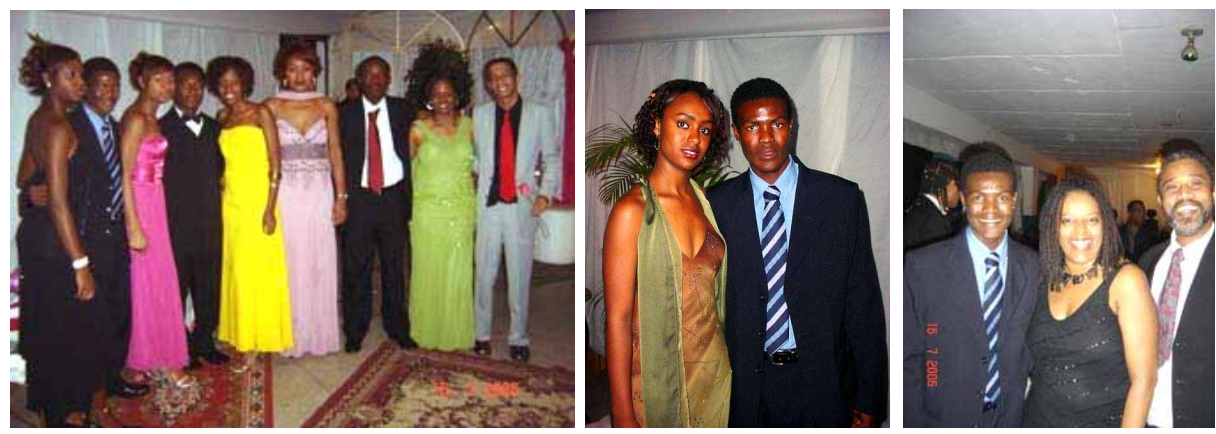

Mas o que também pudemos observar, além desses desdobramentos, foi que as nossas IES e as comunidades acadêmicas (docentes, discentes e funcio-

10. Fonte: <http://www.universia.com.br/html/noticia/noticia_dentrodocampus_bjfhf.html>. Matéria do dia 03 de maio de 2005, com o título "Angolanos na Unesp/São José do Rio Preto".

11. Fotos tiradas no dia 16 de julho de 2006.

Extraído de <http://www.faac.unesp.br/fotos/bailecarmo/?menu_esq I = institucional > . 
nários) não estavam preparadas para lidar com as dificuldades e mesmo com as atitudes expressas por esses jovens, bem como ignoravam a realidade social, política, econômica e cultural de Angola. Com isso, muitos jovens foram vistos a priori como seres exóticos oriundos de culturas arcaicas e portadores de costumes tribais. Foram percebidos como "tímidos e excessivamente educados", mas não como inteligentes e de raciocínio rápido, como os jovens brasileiros.

Os acadêmicos das duas universidades (Unesp e UFPR) das áreas de Ciências Exatas, Tecnológicas, Biológicas e Humanas não estudaram o continente africano e apreenderam uma realidade africana a partir dos veículos midiáticos, mas não se aprofundaram e nem ao menos chegaram a problematizar a realidade vivenciada por esses jovens que cresceram no contexto da guerra civil, muitos dos quais filhos de famílias assimiladas, segundo a lógica e a força empreendida pelo colonialismo português em Angola, em particular nas cidades (Luanda, Benguela, Cabinda e Lubango) de onde são originários, situadas nas franjas do Oceano Atlântico ou influenciados por ele. Nessa região, sobretudo após 1960, concentrou-se a maior parte da população conquistadora lusa, que impôs diversas práticas culturais ocidentais, inclusive o estatuto do indigenato (Bender, 2004; Hodges, 2002), em contrapartida à assimilação.

Talvez em razão desse pouco conhecimento a respeito da cultura que traziam esses jovens, carregava-se nos estereótipos e nos preconceitos acerca de uma África selvagem, de um lado; de outro, consideravam-se os jovens polidos demais, quase europeus; portanto, bastante civilizados, a despeito de serem negros e africanos. Aliás, outro estereótipo construído na sociedade brasileira, referente aos negros no Brasil, sobretudo com relação à polícia militar e ao fato de serem negros, antes de qualquer nacionalidade, também atingiu os estudantes angolanos da Unesp de Bauru, mesmo havendo a orientação da PróReitoria de Extensão Universitária da Unesp (Proex) relativa às questões de segurança e cuidados pessoais ${ }^{12}$. Veja a matéria abaixo:

ALUNOS UNIVERSITÁRIOS NEGROS DA UNESP SOFREM DISCRIMINAÇÃO DA POLÍCIA MILITAR EM BAURU

No último domingo, 25/03/07, à noite senti na pele a realidade da truculência da polícia de Bauru, realidade essa que já era clara para muitos, mas ainda desconhecida para mim. Éramos eu e mais quatro amigos angolanos no carro tentando achar o caminho da chácara que ficava nos limites entre Bauru e Agu-

12. Fonte: <http://www.unesp.br/proex/universia/iha_recebe_angolanos.php > . Matéria intitulada: "Unesp/llha Solteira recebe estudantes angolanos", do dia 24 de maio de 2005. 
dos. Depois de nos perdermos, após tentativas frustradas de encontrar o caminho, notamos que havia policiais atrás do carro em que estávamos, sinalizando para que reduzíssemos. Ao pararmos, policiais abordaram o carro de maneira brutal, apontando-nos armas de alto calibre e gritando "todo mundo pra fora do carro com a mão na cabeça”. Era uma situação inédita para mim. A brutalidade foi tamanha que a única coisa que me veio à mente foram aqueles episódios da polícia de São Paulo, que mata pessoas que julgam culpadas e as desovam em algum lugar. Tremia, chorava. Um dos policiais voltou-se para mim e disse que se estava chorando deveria ter alguma culpa. Depois de passar por revista, como os demais garotos, vasculharam minha bolsa, averiguaram se tinha passagem policial e ainda mexeram na foto de meu namorado e perguntaram "se esse maluco estava preso". Ao se assegurarem de que não tínhamos nada, que éramos todos estudantes da Unesp e os garotos participantes de um convênio entre a universidade e Angola, desculparam-se alegando que tudo era apenas procedimento de rotina. ${ }^{13}$

Todos estes fatos sociais e eventos culturais têm propiciado que esses jovens estudantes angolanos construam nas suas IES novos diálogos com sujeitos diferentes daqueles com que estavam acostumados a lidar na sociedade angolana. Isso ocorre em Curitiba e nas diversas cidades do interior do Estado de São Paulo, tais como São José do Rio Preto, Bauru, Guaratinguetá, Jaboticabal, Ilha Solteira e Presidente Prudente, que são aquelas que reúnem o maior número de estudantes angolanos oriundos do convênio em pauta. Com isso, eles estabelecem, também, novas sínteses identitárias propiciadas pelos seus contatos pessoais e afetivos com amigos brasileiros que vão conquistando e por outras práticas culturais apreendidas no contato com outros alunos, docentes, funcionários, instituições acadêmicas e de pesquisa. Sobretudo, porém, relacionam-se com o universo exterior a essas universidades, como o mercado, as lojas, os bares e restaurantes, os ônibus, os vizinhos e os proprietários das repúblicas onde residem.

\section{Passado, presente e futuro: a tripla perspectiva}

Os jovens estudantes angolanos encontram hoje, em seu país natal, condições bem diferentes daquelas que deixaram quando migraram para o Brasil a fim de efetuar os seus próprios sonhos e de seus familiares: estudar e formar-se

13. Entrevista fornecida por Luana Nascimento - estudante de jornalismo da Unesp de Bauru - 28/03/ 07, concedida ao jornal O Povo de Bauru. Extraído do site da Fundação Cultural Palmares - <http:/ /www.palmares.gov.br/005/0050200 I.jsp?ttCD_CHAVE=299 > . Acesso em: I 8 set. 2008. 
fora de Angola e, em especial, no Brasil, país com o qual eles constituíram positivamente um vínculo afetivo, cultural e político, sobretudo após a sua independência, em 1975. Os jovens angolanos estudantes no Brasil, particularmente em São Paulo e no Paraná, participantes dos convênios da Fesa, encontram-se com a missão pessoal e institucional de retornar ao seu país natal e às suas províncias (Estados), a fim de dar a sua contribuição à reconstrução do país, nas áreas em que estão se formando na graduação, seja no bacharelado ou na licenciatura. No entanto, muitos hesitam em voltar e buscam instalar-se definitivamente no Brasil ou aqui permanecer mais tempo, para fazer a sua pós-graduação, como podemos verificar nas palavras abaixo:

Para Sandra e Valentim, por exemplo, os planos são de usá-lo aqui mesmo, no Brasil. Embora reconheçam que em Angola deva haver mais possibilidades de emprego para mão-de-obra qualificada, como serão, ambos pretendem constituir família em território brasileiro. "Aqui a qualidade de vida é melhor", justifica Sandra. Para Olga e Pedro, entretanto, apesar de atraente, a idéia de viver no Brasil depois de formados não é mais forte que a vontade de voltar a Angola e ajudar na reconstrução do País, que só há 5 anos conseguiu livrar-se de uma guerra civil. $^{14}$

O desejo anunciado por Sandra e Valentim parece estar presente em diversos estudantes universitários angolanos e também em outros estudantes universitários africanos, oriundos do PEC-G, além desse convênio em que a Fesa atua como supervisora e faz o acompanhamento desses estudantes. $\mathrm{O}$ quadro pintado por Sandra e Valentim, bem como aquele desenhado por Olga e Pedro, estabelece o parâmetro do comprometimento desses jovens com a realidade e o cenário histórico angolano.

A situação descrita acima não implica simpatia ou vínculo com nenhum dos partidos políticos opostos que disputam a hegemonia política no país, o Movimento Popular de Libertação de Angola - MPLA — ou União Nacional para a Independência Total de Angola — UNITA —, mas sinaliza o apoio e a vontade de colaborar com o governo, com o país e com o povo angolano. Embora os estudantes não se vejam comprometidos e responsáveis pela guerra civil, com a destruição do país, estão sintonizados com os esforços de reconstrução. Esse sentimento, todavia, os abala, os faz hesitar, pois o desejo de permanecer no Brasil é muito forte nos estudantes angolanos, mesmo tendo ciência de que poderão conseguir excelentes empregos em Angola, já que voltam

14. <http://www.universia.com.br/noticia/materia_dentrodocampus.jsp?not=38700>. Matéria de 31/08/2007. 
com uma formação no exterior e, particularmente, em boas universidades brasileiras.

Assim, a identidade desses jovens será construída, também, a partir da possibilidade de consumir bens dentro de um mercado capitalista com produtos variados e com preços mais acessíveis do que aqueles presentes no comércio das cidades angolanas de onde são originários. Portanto, há uma identidade capitalística (Deleuze apud Fonseca, 2000) que concorre com outras possibilidades de ser, de ter e de estar, permanecendo no Brasil.

As questôes identitárias (Barth, 1998) e de representaçôes sociais (Goffman, 1982; 1989) estão alicerçadas pelo papel e pelo uso que a língua portuguesa no Brasil desempenha como fator catalisador, de proximidade e de encontro com uma língua estudantil nova, cheia de gírias, de dinamismo, como aquela que os jovens angolanos estão forjando no dia-a-dia, no interior de suas famílias e nas ruas de Angola, como o calão. O fato de imitar o linguajar brasileiro expresso na televisão em novelas, principalmente da Rede Globo de Televisão, como "Malhação", dá conta de que esses jovens estabelecem também novos padrões culturais e comportamentais, distintos da realidade angolana. Os jovens brasileiros e angolanos vão aos poucos descobrindo-se e entendendo-se.

A idéia de retornar faz com que os angolanos se confrontem com um contexto natal em que a pressão e o fantasma da guerra civil falam muito alto. $\mathrm{O}$ medo e a falta de liberdade estão presentes nesse universo estudantil e dão base para esses sonhos, fantasias e desejos de não retornar ao país natal. A história antiga e a recente de guerras contínuas enfrentadas pelo povo angolano permeiam as perspectivas sobre o lugar futuro a ser ocupado por esse jovem estudante. Esse processo também está presente na constituição psíquica e cultural do intelectual e do professor universitário em Angola, que vivenciou esse período de precariedade, de fragilidade e de insegurança constantes, mas receia o amanhã que virá, ainda cerceado pelo poder onisciente e onipresente do partido governista (Hodges, 2002). Assim, persiste a dúvida entre querer sair do país ou manter-se nele; persiste a hesitação desses estudantes e docentes - que pensam a realidade angolana - em voltar.

No contexto vivenciado pelos jovens angolanos intercambistas no Brasil constata-se, também, que há um imaginário social que os vincula ao estigma e ao estereótipo do refugiado de guerra, pois são cotidianamente solicitados a falar da guerra civil, da memória dos canhões e das minas, como se tivessem fugido ou saído do país a pé; ou como se Angola ainda se mantivesse em período de guerra. Esse imaginário que constrói a marca do refugiado perene é constituído pela desinformação, pela informação e pela contra-informação produzidas pelos agentes midiáticos nacionais e internacionais, que não produzem outra Angola e, mais genericamente, outra África que não seja a da guerra, 
da miséria, das tribos e dos animais selvagens presentes nas savanas.

Ao interpretarmos esse contexto, fica nítido que a marca simbólica e subliminar do refugiado de guerra é mais forte do que a do migrante temporário, do estudante endinheirado e bem situado na estrutura piramidal de seu país, que quer manter-se no Brasil, mas com o argumento de continuar os seus estudos, agora os cursos de pós-graduação e de especialização. Esse não é o caso dos estudantes que se apresentam nas fotos abaixo: Luege Peliganga, aluna do Curso de Pós-Graduação em Gerenciamento de Obras, na Universidade CefetPR e Augusto Ngangula e Silva, que já se graduou em Ciências Econômicas, na Universidade Federal do Paraná. Como a maioria dos que concluem a graduação, ele também pretende fazer um curso de pós-graduação no Brasil, a despeito de suas dificuldades financeiras e da falta de apoio da Fesa para os cursos de pós-graduação. Ela, Luege Peliganga, sugere que os "governos do Brasil e de Angola deveriam resolver essa questão de modo que pudéssemos exercer atividades remuneradas para custear nossos estudos" $" 15$, pois se encontram com o visto temporário de migrante.
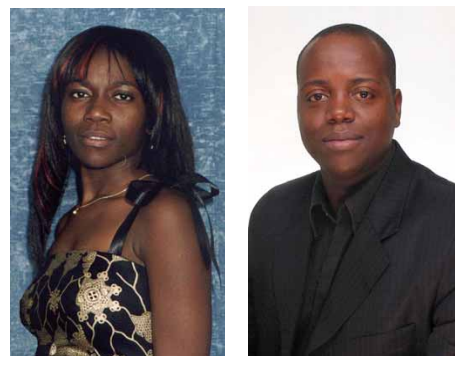

Em síntese, verificamos, com essa reivindicação, que há muitos caminhos a percorrer pelos estudantes angolanos no Brasil, mas também por nossa diplomacia e por nossas universidades, no atendimento aos estudantes africanos oriundos dos Palop, mesmo com os acordos firmados pela CPLP (Comunidade dos Países de Língua Portuguesa) e pelas IES constituintes da Associação de Universidades de Língua Portuguesa (Aulp), particularmente a partir do Protocolo de Cooperação entre a CPLP e a Aulp, assinado em 17 de julho de 2000.

Interpretamos, ainda, que a identidade capitalística, como demonstra Deleuze (apud Fonseca, 2000), forja a identidade desses jovens angolanos que buscam, antes, no conforto, nos bens materiais, na sociedade de consumo, no estilo de vida - fatores calcados, fundamentalmente, no sistema capitalista de produ-

15. Fonte: < http://www.fesa.org.br/Imprensa/AngolaHoje/2004/Mai-Jun/pagl8.htm>. Matéria intitulada: "Angolanos formados no Brasil com apoio da Fesa buscam especialização". 
ção material e simbólica - o seu lugar no mundo. Portanto, a tripla perspectiva (a vinda, a permanência e a volta) gera esquizofrenia, sentimento de falta de lugar, pois sabem que não encontrarão mais os mesmos amigos, os mesmos familiares, a mesma cidade e o mesmo país quando voltarem; têm ciência de que as suas referências identitárias, os seus vínculos sociais e afetivos se modificaram durante o período de permanência no Brasil. Além disso, sabem também que não são independentes, necessitam dos recursos financeiros que são enviados por muitas pessoas e mesmo por governantes, para permanecerem no Brasil.

O fato é que a migração desses jovens altera profundamente a maneira de enxergarem o mundo, pois estão sendo inseridos em um universo diferente daquele que deixaram e, ainda, permanecem um período relativamente curto - quatro ou cinco anos para obterem o título de bacharel e/ou licenciado no país anfitrião, mas carregado de novidades resultantes de sensações, de cobranças, de sonhos, de angústias, de contatos e de conhecimentos novos que propiciam a constituição de novos sujeitos socioculturais, históricos e psíquicos, na medida em que se transformam paulatinamente diante da avalanche de informaçôes científicas, midiáticas e hormonais que os faz cada vez mais diferentes e estranhos diante de um cotidiano multifacetado, plural e altamente dinâmico, em decorrência dessas perspectivas que os mobiliza para estarem física e sentimentalmente em Angola e/ou no Brasil.

É nesse contexto dinâmico que se constroem identidades e representações sociais diversas, inclusive a possibilidade de assistir aqui à diluição dos sentimentos étnico e regional, fortalecendo, em contrapartida, a concepção da nação. Angola aparece no Brasil sem o peso da referência étnica ou regional, mas como país idílico a ser construído de maneira crítica por essa geração nascida no contexto da guerra.

Nesse contexto, há que se pautar também o atendimento às metas do milênio assumidas pelo governo de Angola quanto a ampliar o número de vagas na Universidade Agostinho Neto; possibilitar, com rapidez e qualidade, a abertura de cursos pelas faculdades e universidades privadas do país, para o justo atendimento das demandas juvenis por IES constituídas em pleno século XXI em solo africano, particularmente em Luanda; também quanto a criar e incentivar outras IES, especialmente em locais distantes do litoral e das áreas hegemonizadas pela etnia kimbundu.

\section{Referências bibliográficas}

BARTH, Fredrik. Grupos étnicos e suas fronteiras. In: POUTIGNAT, Philippe; STREIFFFERNART, Jocelyne (Org.). Teorias da etnicidade. São Paulo: Unesp, 1998. p. 185-227. 
BENDER, Gerald J. Angola sob o domínio português - mito e realidade. Coleção Ensaio, Luanda, n. 21, 2004.

DESIDÉRIO, Edilma. Migração e políticas de cooperação: fluxos entre Brasil e África. In: ENCONTRO NACIONAL SOBRE MIGRAÇÃA, 4, 16-18 de novembro de 2005, Rio de Janeiro-RJ. Texto para comunicação em Sessão Temática 1-Migração Internacional. p. 23.

FONSECA, Dagoberto José. Corpos negros (i)maculados: mulher, catolicismo e testemunho. 2000. Tese (Doutorado) — Programa de Estudos Pós-Graduados em Ciências Sociais, Pontifícia Universidade Católica de São Paulo, São Paulo.

FONSECA, Dagoberto José. Relatório viagem ao exterior Vestibular-Angola. São Paulo: Nupe; Unesp, 2005. p. 1-5.

FUNDAÇÃO VUNESP. Edital de acesso 2005 - vestibular em Angola para universidades do Brasil. São Paulo: Vunesp, 2004. p. 1-22.

GALA, Irene Vida. A politica externa do governo Lula para a África: a política externa como instrumento de ação afirmativa ... ainda que não só. $51^{\circ}$ Curso de Altos Estudos, Brasília. Instituto do Rio Branco, Ministério das Relações Exteriores, 2007, p. 258.

GOFFMAN, Erving. Estigma: notas sobre a manipulação da identidade deteriorada. Rio de Janeiro: Zahar, 1982.

GOFFMAN, Erving. A representação do eu na vida cotidiana. Petrópolis: Vozes, 1989.

HODGES, Tony. Angola: do afro-estalinismo ao capitalismo selvagem. Cascais: Principia, 2002.

SARAIVA, José Gomes; GALA, Irene Vida. O Brasil e a África no Atlântico Sul: uma visão de paz e cooperação na história da construção da cooperação africano-brasileira no Atlântico Sul. Disponível em: <http://bibliotecavirtual.clacso.org.ar/ar/libros/aladaa/sombra.rtf $>$. Acesso em: 18 set. 2008.

Recebido em 15 de julho de 2008 e aprovado em 26 de setembro de 2008. 